RESEARCHARTICLE

\title{
Factors Associated with Loss of Skin-Plantar Sensitivity and Diabetic Foot Risk in Elderly with Diabetic Neuropathy: Cross- Sectional Study
}

\author{
Fabiana Magalhães Navarro-Peternella ${ }^{1 *}$, Elen Ferraz Teston $^{2}$, and Sonia Silva \\ Marcon $^{3}$
}

${ }^{1}$ Health Sciences at State University Maringá, Paraná, Brazil

${ }^{2}$ State University Paraná, Paraná, Brazil

${ }^{3}$ Health Sciences and Nursing, State University Maringá, Paraná, Brazil

Open Access

Citation: Navarro-Peternella, FM, Teston EF, Marcon SS. Factors Associated with Loss of SkinPlantar Sensitivity and Diabetic Foot Risk in Elderly with Diabetic Neuropathy: Cross-Sectional Study. Endocrinology, Diabetes and Obesity. 2018; 1(1):3.

Received: Mar 13, 2018

Accepted: May 21, 2018

Published: June 05, 2018

Copyright: @ 2018 Navarro-Peternella FM, Teston EF, Marcon SS. This is an open access article distributed under the terms of the Creative Commons Attribution License, which permits unrestricted use, distribution, and reproduction in any medium, provided the original author and source are credited.

Corresponding author:

Fabiana Magalhães Navarro-Peternella, Health Sciences at State University Maringá, Paraná, Brazil

E-mail: navarrofabiana@gmail.com

\begin{abstract}
Background: The Diabetes Mellitus type 2 (DM2) can cause sensory motor complications in the feet, damaging the plantar sensitivity. The aim of the study was to identify factors associated with loss of skin-plantar sensitivity and diabetic foot risk in elderly patients with peripheral neuropathy.

Methods: 151 elderly patients with Type 2 Diabetes Mellitus and symptoms of diabetic neuropathy of a Health Unit of Maringá-PR participated in the study. The clinical condition of the feet, the level of physical activity, the plantar cutaneous sensitivity and the diabetic foot risk were evaluated. For the association between the variables, the chi-square test $2 \times 2$ (or Fisher's Exact) and chi-square trend $(p<0.05)$ were used.

Results:Low income $(p<0.001)$ and the absence of family background of DM $(p<0.004)$ was associated with the loss of skin-plantar sensitivity and low-income with the risk of diabetic foot ( $p$ 0.018). Regarding the overall health of the feet, the presence of calluses is associated with loss of skin-plantar sensitivity $(p<0.002)$ and the risk of diabetic foot ( $p$ $<0.006)$.

Conclusion: The elderly with diabetic neuropathy, especially those with low income and presence of calluses in the feet, should be given greater care and individualized attention from health professionals to prevent the development of major complications, ulcer and amputation.
\end{abstract}

\section{Keywords}

Elderly, diabetes mellitus, diabetic foot, diabetic neuropathy, health service.

\section{Introduction}

The prevalence of diabetes mellitus (DM) has been worrying many countries because the rates are alarming.$^{1-3}$ The type 2 diabetes mellitus (DM2) has reached 220 million people worldwide, with 370 million forecasts for $2030{ }^{4,5}$ In the United States there are over 20 million diabetics, in England or in Malta, a small island in the Mediterranean, over $10 \%$ of seniors over 75 years have DM. ${ }^{6,7}$ And in Brazil, the rates are more worrying because $20 \%$ of individuals over 65 are already diabetic. ${ }^{8}$

The DM2 is the most prevalent, responsible for $90 \%$ of cases and its development arise from a combination of factors, such as inadequate life habits, advanced age of the population and genetic factors, however, it is a major concern in the development of complications, which in their frequency and severity become chronic., ${ }^{9,10}$ The peripheral neuropathy or diabetic neuropathy is one, it can affect $20 \%$ to $75 \%$ of diabetics. ${ }^{7,11,12}$ It is caused by axonal 
degeneration and demyelination of large somatic fibers, which triggers a progressive loss of skin-plantar sensitivity. ${ }^{13}$

The reduction in skin-plantar sensation undertakes the necessary feedback to the maintenance of balance and motor stability during walking and the development of some activities of daily living. ${ }^{11,13,14}$ This reduction can also lead to increased pressure on certain areas of the foot, such as foot deformities, calluses and hallux valgus, cause the formation of an area of higher pressure that can predict the development lesions and lack vascularization. increasing the risk of amputation $[9,15]$ and causing greater expenses for the health system. ${ }^{1,4,9,14-16}$ The prevalence of reduced plantar skin sensation increases with age and there is a lack of information and control measures, especially among the low income population and education. ${ }^{17-19}$

These neurological and vascular changes in extremities of lower limbs, characterize the diabetic foot and can produce anatomical and physiological changes of the feet along with infection, ulceration and / or destruction of deep tissues. The change in muscle strength and sensitivity can cause pressure points to arise, which, together with the presence of areas of dryness in the feet, impairs the skin's elasticity and local circulation, increasing the risk of foot ulcers. $^{20}$

Therefore, the diabetic foot results from a combination of several factors, such as sensorymotor neuropathy, peripheral vascular disease, biomechanical changes, leading to abnormal plantar pressure, and possible infections, damaging the clinical condition of the diabetic foot.20 The early identification of factors predisposing to the development of foot ulceration and the planning of intervention strategies is a necessity for disease control. ${ }^{1}$

Thus, considering that the identification of the factors that are related to the loss of plantar cutaneous sensitivity in the elderly with DM, could more specifically target prevention of diabetic foot by the health team, the objective of this study was to identify factors associated with loss of skin-plantar sensitivity and diabetic foot risk in elderly patients with peripheral neuropathy.

\section{Methods}

\section{Type of study and sample}

It is a cross-sectional study. Whereas the profile of older people with DM2 is very similar in the different Basic Health Units e city, and there was a random drawing from the records of elderly patients with DM2 of a Basic Health Unit. ${ }^{21}$ At this level of care the elderly when seeking service undergo medical consultation and receive free of charge the necessary medication to control the disease and, where necessary, they are sent to specialized consultation, but these are limited and the waiting time can be long.

Study participants included ( $N=187$; over 60 years of age) patients with type 2 diabetes and symptoms of diabetic neuropathy, identified from the report of pain, tingling, burning or numbness in the feet or absence of protective sensation (10 grams filament) in at least one of the six evaluated plantar regions.

The exclusion criteria were individuals diagnosed with type 2 diabetes for less than a year, with stroke consequences (stroke), peripheral vascular disease metabolic disorders (hypothyroidism or uremia), nutritional neuropathies (alcoholism), toxic neuropathies and malignancies, and no clinical signs or symptoms of diabetic neuropathy, though not all of these conditions were found among the evaluated elderly patients. Finalizing 151 elderly people for the study (Figure 1). 
Figure 1. Study design diagram

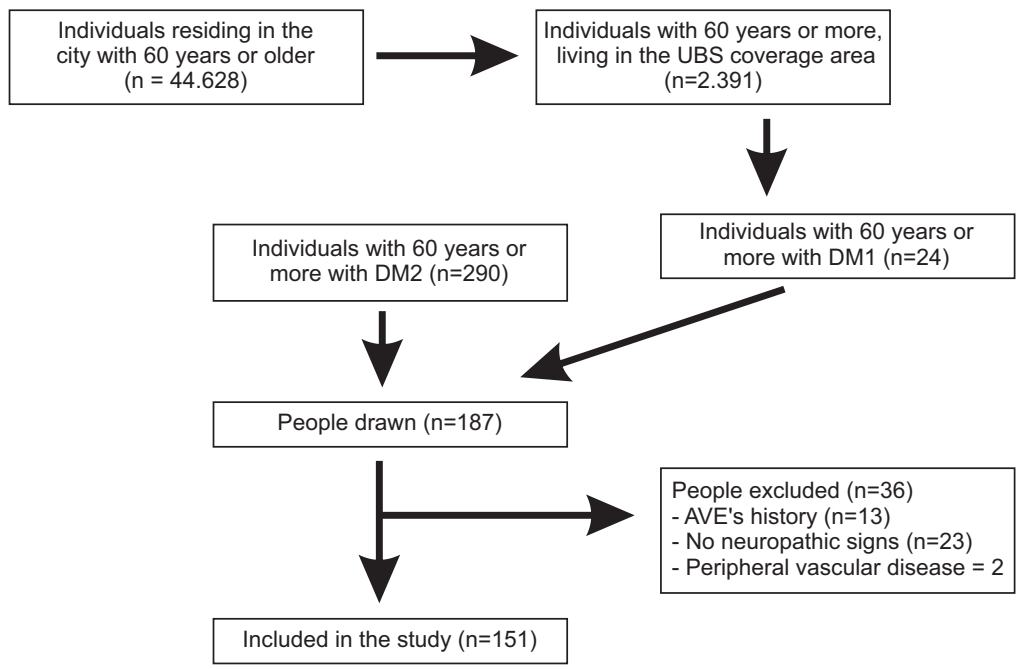

To calculate the sample size was estimated a prevalence of peripheral neuropathy of $50 \%$, an error of $5 \%$ and drawing effect of 1.0 for an infinite sample of individuals over 60 who had type 2 diabetes. ${ }^{12}$

Reviews and interviews were scheduled by phone and individually held at unity health, with a duration of 20 to 30 minutes. To evaluate the general health it was investigated the presence of comorbidities or complications (visual or hearing impairment, arterial hypertension, heart failure, arrhythmia, osteoarthritis, depression, cancer, labyrinthitis), clinical data of DM2 and physical activity level with application of IPAC (International Physical Activity Questionnaire), ranked as very active, active, irregularly active and sedentary according to energy expenditure in a typical week and in work-related activities, transportation, housekeeping, leisure and sitting time..$^{22,23}$

When the elderly person spends more than 150 minutes in such activities, he is classified as active; when he spends less than 150 minutes is classified as insufficiently active, and when he does not perform any physical activity for at least 10 continuous minutes during the week, he is considered sedentary. ${ }^{22}$

The nutritional status was determined based on the Body Mass Index (BMI = weight $/$ height ${ }^{2}$ ), which was measured in anthropometric mechanical scale and classified the elderly person as normal $\left(\mathrm{BMI}=18,5\right.$ to $\left.24,9 \mathrm{Kg} / \mathrm{m}^{2}\right)$, overweight $\left(\mathrm{BMI}=25,0\right.$ to $\left.29,9 \mathrm{Kg} / \mathrm{m}^{2}\right)$ and obesity $\left(\mathrm{BMI} \geq 30,0 \mathrm{Kg} / \mathrm{m}^{2}\right)^{23}$

Feet health of elderly was determined from the observation of the presence of calluses and keratoses, followed by the lifting of subjective data regarding the presence of pain, numbness, tingling and feet burning. To evaluate skin-plantar sensitivity, we used Semmes-Weinstein filaments, which once applied to the foot surface exert a force of 0,$2 ; 2,0 ; 4,0 ; 10$ and 300 grams. ${ }^{24}$ We evaluated six plantar region of the feet: $1 \mathrm{st}$, 3rd and 5 th toe, one medial point and one lateral point in the tarsal region and one point in the calcaneus, starting with the less dense monofilament, and in the absence of response we proceeded with the following and so on, until the individual accused some sensitivity. ${ }^{25,26}$ It was considered lost plantar sensitivity when the individual did not show sensitivity to 10 grams of fiber in any of the points assessed on any of the feet. ${ }^{27}$

The risk of diabetic foot was determined by a six-point scale: 0 - intact and preserved sensitivity, 1 - loss of plantar protective sensation, 2 - loss of plantar protective sensation and deformity / plantar pressure increase, 3 - loss of plantar protective sensation and previous ulcer history, 4 - loss of plantar protective sensation and previous ulcer history with deformity or increased plantar pressure and 5 - Presence of neuropathic fracture [28], from related to external factors on interview.

\section{Statistical Analysis}

The normality of the data was tested by Shapiro-Wilk test. The descriptive analysis involved the use of the median (Med) and the interquartile range (IQR) and, absolute (n) and relative (\%) frequencies. Associations between general characteristics of the sample and socio- 
demographic factors and clinical complaints with loss of sensation and risk ratings were assessed using the chi-square $2 \times 2$ test (or Fisher's Exact) and the chi-square of trend (for associations that involved polytomous variables). The level of significance was set at $p<0.05$. All analyzes were conducted using IBM SPSS Statistics 2.0.

All procedures performed in studies involving human participants were in accordance with the ethical standards of the institutional and/or national research committee (opinion no $353,067)$. Informed consent was obtained from all individual participants included in the study.

Part of a randomized clinical trial registered with

REBEC (RBR-8hfcz8) http://ensaiosclinicos.gov.br/rg/RBR-8hfcz8/

\section{Results}

The average age of the elderly in the study was 70.6 years (median $=70.3 ; \mathrm{IQR}=7.3$ ), more than half were female and had a partner $(62.9 \%)$. Most had low education, with a maximum of eight years of education (74.1\%) and $13.2 \%$ were illiterate. Regarding family income, $71.5 \%$ lived with one to three minimum wages (262-788 \$). The DM diagnosis ranged from one to 40 years $(\mathrm{Med}=10.4 ; \mathrm{IQR}=8.3)$, more than half had a family history of DM $(57.6 \%)$ were sedentary $(57.6 \%)$ and most were overweight or obese $(70.7 \%)$ (Table 1$)$.

Table 1. Clinical and sociodemographic characteristics according to the loss of plantar sensitivity

\begin{tabular}{|c|c|c|c|c|c|c|}
\hline \multirow{3}{*}{ Characteristics } & & \multicolumn{4}{|c|}{ Loss of plantar skin sensibility } & \multirow[b]{3}{*}{$P$} \\
\hline & & \multicolumn{2}{|c|}{$\begin{array}{c}\text { Yes } \\
(n=41)\end{array}$} & \multicolumn{2}{|c|}{$\begin{array}{c}\text { No } \\
(n=110)\end{array}$} & \\
\hline & & $\mathrm{N}$ & $\%$ & $\mathrm{~N}$ & $\%$ & \\
\hline \multirow[t]{2}{*}{ Age (years) } & $\leq 70$ & 21 & 51.0 & 65 & 60 & 0.279 \\
\hline & $>70$ & 20 & 49.0 & 46 & 40 & \\
\hline \multirow[t]{2}{*}{ Diagnostic (years) } & $\leq 10$ & 20 & 49.0 & 75 & 68.2 & 0.086 \\
\hline & $>10$ & 21 & 51.0 & 35 & 31.8 & \\
\hline \multirow[t]{2}{*}{ Gender } & Male & 18 & 44.0 & 43 & 61 & 0.592 \\
\hline & Female & 23 & 56.0 & 67 & 49 & \\
\hline \multirow[t]{2}{*}{ Marital status } & With companion & 24 & 58.5 & 71 & 64.5 & 0.496 \\
\hline & $\begin{array}{l}\text { Without } \\
\text { companion }\end{array}$ & 17 & 41.5 & 39 & 35.5 & \\
\hline \multirow[t]{2}{*}{ Education } & $\leq 8$ years of study & 31 & 75.6 & 81 & 73.6 & 0.800 \\
\hline & $>8$ years of study & 10 & 24.4 & 29 & 26.4 & \\
\hline \multirow[t]{2}{*}{ Family income (MW) } & $1-3$ & 36 & 87.8 & 72 & 65.4 & $0.001^{*}$ \\
\hline & $\geq 4$ & 5 & 12.2 & 38 & 34.6 & \\
\hline \multirow[t]{2}{*}{ Family background } & Yes & 17 & 41.5 & 70 & 63.6 & $0.014^{*}$ \\
\hline & No & 24 & 58.5 & 40 & 36.4 & \\
\hline \multirow[t]{2}{*}{ Insulin use } & Yes & 11 & 26.8 & 24 & 21.8 & 0.516 \\
\hline & No & 30 & 73.2 & 86 & 78.2 & \\
\hline \multirow[t]{3}{*}{ Nutritional status } & Normotrophic & 11 & 26.8 & 33 & 30.0 & 0.831 \\
\hline & Overweight & 17 & 41.5 & 42 & 38.2 & \\
\hline & Obesity & 13 & 31.7 & 35 & 31.8 & \\
\hline \multirow[t]{2}{*}{ Physical Activity } & Asset & 14 & 34.2 & 50 & 45.5 & 0.211 \\
\hline & Very active & 27 & 65.8 & 60 & 54.5 & \\
\hline
\end{tabular}

Note: MW - Minimum wages (1 Wages $=880.00$ reais/2016); IPAC - International Physical Activity Questionnaire). Chi-square test $2 \times 2$ with significance level at * $p<0.05$ )

Among the comorbidities presented by the patients, arterial hypertension was the most prevalent $(82.8 \%)$, followed by osteoarthritis $(39.7 \%)$. It was also found a presence of visual / hearing loss $(26.5 \%)$, heart failure / arrhythmia (23.1\%), labyrinthitis (14.5\%), depression $(7.3 \%)$ and history of cancer $(6,0 \%)$.

Amid the clinical and socio-demographic characteristics the loss of plantar sensitivity was associated with a lower income and a lack of family history of the disease, which was a protective factor for the development of plantar sensitivity loss (OR: 0.4 and $p<0.05$ ). The loss of plantar sensitivity was more frequent among elderly with a delayed diagnosis of the disease (Table 1).

In clinical complaints, only the presence of calluses on feet was significantly associated with 
impaired plantar sensitivity (OR: 3.2; p <0.002) (Table 2).

Table 2. Associations between clinical complaints compared to foot and loss of plantar sensitivity

\begin{tabular}{|c|c|c|c|c|c|c|}
\hline \multirow{3}{*}{$\begin{array}{l}\text { Clinical } \\
\text { Complaints }\end{array}$} & & \multicolumn{4}{|c|}{ Loss of plantar sensitivity } & \multirow[b]{3}{*}{$P$} \\
\hline & & \multicolumn{2}{|c|}{ Yes $(n=41)$} & \multicolumn{2}{|c|}{ No $(n=110)$} & \\
\hline & & $\mathrm{N}$ & $\%$ & $\mathrm{~N}$ & $\%$ & \\
\hline \multirow[t]{3}{*}{ Calluses } & & & & & & $0.002^{*}$ \\
\hline & Present & 28 & 68.3 & 44 & 40 & \\
\hline & Absent & 13 & 31.7 & 66 & 60 & \\
\hline \multirow[t]{3}{*}{ Keratosis } & & & & & & 0.424 \\
\hline & Present & 30 & 73.2 & 73 & 66.3 & \\
\hline & Absent & 11 & 26.8 & 37 & 33.7 & \\
\hline \multirow[t]{3}{*}{ Pain } & & & & & & 0.117 \\
\hline & Present & 18 & 43.9 & 64 & 58.2 & \\
\hline & Absent & 23 & 56.1 & 46 & 41.8 & \\
\hline \multirow[t]{3}{*}{ Numbness } & & & & & & 0.479 \\
\hline & Present & 25 & 61.0 & 60 & 54.5 & \\
\hline & Absent & 16 & 39.0 & 50 & 45.5 & \\
\hline \multirow[t]{3}{*}{ Pricking } & & & & & & 0.256 \\
\hline & Present & 21 & 51.2 & 45 & 40.9 & \\
\hline & Absent & 20 & 48.8 & 65 & 59.1 & \\
\hline \multirow[t]{3}{*}{ Burning } & & & & & & 0.629 \\
\hline & Present & 15 & 36.6 & 45 & 40.9 & \\
\hline & Absent & 26 & 63.4 & 65 & 59.1 & \\
\hline
\end{tabular}

Note: Chi-square test $2 \times 2$ with significance level at ${ }^{*} \mathrm{P}<0.05$ )

The table 3 shows that only family income was significantly associated with the risk of developing diabetic foot.

Table 3. Associations between socio demographic and clinical characteristics of elderly with Risk Rating for the diabetic foot

\begin{tabular}{|c|c|c|c|c|c|c|}
\hline \multirow{3}{*}{ Characteristics } & \multicolumn{5}{|c|}{ Risk Rating } & \multirow[b]{3}{*}{$p$} \\
\hline & $\begin{array}{c}0 \\
(n=110)\end{array}$ & $\begin{array}{c}1 \\
(n=28)\end{array}$ & $\begin{array}{c}2 \\
(n=7)\end{array}$ & $\begin{array}{c}3 \\
(n=3)\end{array}$ & $\begin{array}{c}4 \\
(n=3)\end{array}$ & \\
\hline & $\mathrm{N}(\%)$ & $\mathrm{N}(\%)$ & $\mathrm{N}(\%)$ & $N(\%)$ & $\mathrm{N}(\%)$ & \\
\hline Age & & & & & & 0.081 \\
\hline$\leq 70$ years & $61(55.4)$ & $16(57.1)$ & $5(71.4)$ & $2(66.7)$ & $1(33.4)$ & \\
\hline$>70$ years & $49(44.6)$ & $12(42.9)$ & $2(28.6)$ & $1(33.3)$ & $2(66.6)$ & \\
\hline Diagnosis & & & & & & 0.427 \\
\hline$\leq 10$ years & $72(65.4)$ & $14(50.0)$ & $7(100)$ & 1(33.3) & $1(33.4)$ & \\
\hline$>10$ years & $38(34.6)$ & $14(50.0)$ & $0(0.0)$ & $2(66.7)$ & $2(66.6)$ & \\
\hline Sex & & & & & & 0.194 \\
\hline Men & $43(39.0)$ & $10(35.7)$ & $4(57.1)$ & $2(66.7)$ & $2(66.6)$ & \\
\hline Woman & $67(61.0)$ & $18(64.3)$ & $3(42.9)$ & $1(33.3)$ & $1(33.4)$ & \\
\hline Marital status & & & & & & 0.595 \\
\hline With companion & $71(64.5)$ & $17(60.7)$ & $3(42.9)$ & $2(66.7)$ & $2(66.6)$ & \\
\hline Without companion & $39(35.5)$ & $11(39.3)$ & $4(57.1)$ & $1(33.3)$ & $1(33.4)$ & \\
\hline Education & & & & & & 0.785 \\
\hline$\leq 8$ years of study & $95(86.3)$ & $25(89.3)$ & $7(100)$ & $3(100)$ & $2(66.6)$ & \\
\hline$>8$ years of study & $15(13.7)$ & $3(10.7)$ & $0(0.0)$ & $0(0.0)$ & $1(33.4)$ & \\
\hline Family income & & & & & & 0.018 \\
\hline 1 to $3 \mathrm{SM}$ & $72(65.4)$ & 25(89.3) & $5(71.4)$ & $3(100)$ & $3(100)$ & \\
\hline 4 or more & $38(34.6)$ & $3(10.7)$ & $2(28.6)$ & $0(0.0)$ & $0(0.0)$ & \\
\hline Family background & & & & & & 0.067 \\
\hline Yes & $70(63.6)$ & $12(42.9)$ & $2(28.6)$ & $1(33.3)$ & $2(66.6)$ & \\
\hline No & $40(36.4)$ & $16(57.1)$ & $5(71.4)$ & $2(66.7)$ & $1(33.4)$ & \\
\hline Insulin use & & & & & & 0.213 \\
\hline Yes & $24(21.8)$ & $7(25.0)$ & $1(14.3)$ & $1(33.3)$ & $2(66.6)$ & \\
\hline No & $86(78.2)$ & $21(75.0)$ & $6(85.7)$ & $2(66.7)$ & $1(33.4)$ & \\
\hline Nutritional status & & & & & & 0.771 \\
\hline Normotrophic & $33(30)$ & $7(25.0)$ & $2(28.6)$ & $1(33.3)$ & $1(33.3)$ & \\
\hline Overweight & $42(38.2)$ & $14(50.0)$ & $1(14.3)$ & $1(33.3)$ & 1(33.3) & \\
\hline Obesity & $35(31.8)$ & $7(25.0)$ & $4(42.9)$ & $1(33.3)$ & $1(33.3)$ & \\
\hline Level of physical activity & & & & & & 0.354 \\
\hline Asset & $50(45.5)$ & $8(28.6)$ & $4(42.9)$ & $2(66.7)$ & $0(0.0)$ & \\
\hline Non active & $60(54.5)$ & $20(71.4)$ & $3(57.1)$ & $1(33.3)$ & $3(100)$ & \\
\hline
\end{tabular}

Note: SM - Minimum wages (1 Wages $=788.00$ reais); IPAC - International Physical Activity Questionnaire). ${ }^{*} P<0.05$. (Trends Chi-square test with significance level at ${ }^{*} P<0.05$ ) 
The degree of risk of diabetic foot was significantly associated only with the presence of callus $(p<0.006)$ (Table 4$)$.

Table 4. Associations between clinical complaints compared to foot with the Diabetic Foot Risk Classification

\begin{tabular}{|c|c|c|c|c|c|c|}
\hline \multirow[t]{2}{*}{ Characteristics } & \multirow[b]{2}{*}{$\begin{array}{c}0 \\
(n=110) \\
N(\%)\end{array}$} & \multicolumn{4}{|c|}{ Diabetic Foot Risk Classification } & \multirow[b]{2}{*}{$p$} \\
\hline & & $\begin{array}{c}1 \\
(n=28) \\
N(\%)\end{array}$ & $\begin{array}{c}2 \\
(n=7) \\
N(\%)\end{array}$ & $\begin{array}{c}3 \\
(n=3) \\
N(\%)\end{array}$ & $\begin{array}{c}4 \\
(n=3) \\
N(\%)\end{array}$ & \\
\hline Calluses & & & & & & $\underset{*}{0.006}$ \\
\hline Present & $44(40.0)$ & $19(67.8)$ & $5(71.4)$ & $1(33.3)$ & $3(100)$ & \\
\hline Absent & $66(60.0)$ & $9(32.2)$ & $2(28.6)$ & 2(66.7) & $0(0.0)$ & \\
\hline Keratosis & & & & & & 0.400 \\
\hline Present & $73(66.4)$ & $20(71.4)$ & $6(85.7)$ & $1(33.3)$ & $3(100)$ & \\
\hline Absent & $37(33.6)$ & $8(28.6)$ & $1(14.3)$ & 2(66.7) & $0(0.0)$ & \\
\hline Pain & & & & & & 0.813 \\
\hline Present & $64(58.2)$ & $12(42.9)$ & $0(0.0)$ & $3(100)$ & $3(100)$ & \\
\hline Absent & $46(41.8)$ & 16(57.1) & $7(100)$ & $0(0.0)$ & $0(0.0)$ & \\
\hline Numbness & & & & & & 0.277 \\
\hline Present & $60(54.5)$ & 15(53.5) & $6(85.7)$ & $2(66.7)$ & $2(66.7)$ & \\
\hline Absent & $50(45.5)$ & $13(46.5)$ & 1(14.3) & 1(33.3) & 1(33.3) & \\
\hline Pricking & & & & & & 0.283 \\
\hline Present & $45(40.9)$ & $13(46.5)$ & $6(85.7)$ & $0(0.0)$ & $2(66.7)$ & \\
\hline Absent & $65(59.1)$ & $15(53.5)$ & $1(14.3)$ & $3(100)$ & $1(33.3)$ & \\
\hline Burning & & & & & & 0.422 \\
\hline Present & $45(40.9)$ & $10(35.7)$ & $4(57.1)$ & $1(33.3)$ & $0(0.0)$ & \\
\hline Absent & $65(59.1)$ & 18(64.3) & $3(42.9)$ & 2(66.7) & $3(100)$ & \\
\hline
\end{tabular}

Note: (Trends Chi-square test with significance level at ${ }^{*} \mathrm{P}<0.05$ )

\section{Discussion}

The loss of coetaneous plantar sensitivity in the elderly with DM2, associated with other sensor motor symptoms, is the major complication of diabetic neuropathy. ${ }^{15,16}$ In this study, the most frequent sensory symptoms were dormancy and pain, present in more than half of the elderly, followed by loss of protective sensitivity (absence of sensibility to the $10 \mathrm{grams}$ filament). Although there was no significant difference, it was observed that loss of protective sensitivity was present among elderly people who had been living with DM for more than 10 years and who were sedentary. Similar results were found in a study of 147 individuals with peripheral neuropathy in China, who identified an association between the severity of diabetic neuropathy and the time of diagnosis. Such association was attributed to the high glucose levels due to DM, which cause morphological changes and the conduction velocity of the peripheral nerves. ${ }^{12}$

The family history of DM2 constituted a protective factor for the loss of plantar skin sensibility. It is probable that the coexistence with a family member with the disease triggers alert the others about the possible complications and, consequently, sensitization regarding the need for specific care for the control of DM2. The knowledge of DM and its complications is extremely important for the individual and family, once sensor motor alterations are installed, a series of sensory symptoms (loss of skin sensibility, tingling, numbness) begins, culminating in the development of the foot and risk of amputation. ${ }^{10}$ Health education can break this cycle of impairments, since, once better habits of life and adequate pharmacological monitoring have been adopted, the disease tends to be controlled. ${ }^{19}$

A significant association between low family income and loss of coetaneous plantar sensitivity was observed, which corroborates the results of other studies in Brazil which pointed out a relation between the socioeconomic status and the development of DM and its complications. In the present study, it was observed that the majority of the elderly had low levels of schooling, including a considerable number defined as illiterate common reality in countries with lower level of economic development. ${ }^{17,19}$ The large number of individuals with less than eight years of schooling justifies the fact that there was no association of schooling 
with the outcome variables. It is noteworthy that some studies have already indicated a high prevalence of DM2 (greater than 40\%) among the elderly with less than eight years of study. ${ }^{17,19}$

Health status may be associated with daily care and access to information, since it is likely that the individual with better financial conditions will be more careful about health, including glycemic control and foot hygiene. ${ }^{16}$ essential factors for maintaining health. A multicenter study involving seven countries (Argentina, Brazil, Chile, Cuba, Barbados, Mexico, and Uruguay) found that schooling and income influence the prevention of DM complications. For the elderly in particular, income would be an important component for reducing the differences in self-care attributed to education. ${ }^{29}$

These findings point to the need to invest in universal public assistance and preventive policies directed mainly to diabetic elderly people with low income and little schooling, since these conditions, common in countries such as Brazil, difficult to acquire knowledge and guidelines on care with the disease, as well as the adoption of adequate life habits for the control of the disease. ${ }^{30}$

In 2016, the Ministry of Health of Brazil launched the manual of diabetic foot, establishing the need for periodic evaluation of the feet of the elderly, in the Health Unit or home. This assessment should include investigation of foot temperature, color, sensitivity, skin features, deformities, callosities, pedal pulses, edema and presence of ulcers. From this, the risk of diabetic foot is stratified and establishes the frequency of follow-up of this patient, with guidelines and management of the risk conditions. ${ }^{20}$

However, some studies consider cognitive ability as a fundamental factor for health education and behavior, reaffirming the need for investments in health education programs that are more comprehensive and with differentiated population focus, since individuals with higher cognitive ability are more concerned with health and are more involved in physical and preventive activities. $^{29,31}$

Regarding the clinical characteristics, it was observed that the presence of callus increases by more than three times the chance of loss of the protective sensitivity of the feet and, consequently, the possibility of developing diabetic foot. The relationship between neuropathy and the presence of ulcers in the elderly with DM is known, more frequent in men with longer diagnosis and who have peripheral neuropathy. ${ }^{32}$

Peripheral nerve damage is manifested by the presence of dry skin on the feet, which can result in calluses, fissures, and ulcers. Callus may be due to improper use of shoes or biomechanical alteration in the discharge of the weight in the feet during walking. ${ }^{1}$ They occur in people of any age, but due to the lack of sensitivity, are more dangerous in the elderly with DM, since with age occur the loss of the bodies of Meissner and Paccini, responsible for the tactile and pressure sensitivities in the superficial and deep dermis respectively. ${ }^{13}$

Vascular changes or structural deformities, associated with poor glycemic control, may also trigger ulcers, and these can lead to amputation., ${ }^{9,10}$ Ulcers and amputations generate numerous financial expenses with treatments and hospitalizations, and impair the quality of life of the individual, given the physical and even psychological limitations that these conditions can trigger.

Thus, the attention and care of health professionals should be higher when a person is old and low income, together with sensory impairment due to DM, increasing the risk of ulcers and consequent diabetic foot. These modifications bring about important changes to the individual and the society since physical limitations and impairments in quality of life can disable and make the person dependent, interfering in her social and economic activities. ${ }^{7}$ It is also incumbent on health professionals to advise older people on simple measures that should be taken to protect their feet, such as cleaning their feet, wearing comfortable shoes, hydrating their feet, taking care of possible injuries and even some metabolic ankle so as to stimulate circulation and better oxygenation of tissues.

Some important variables were not evaluated and investigated among the elderly, constituting a limitation of the study, such as evaluation of self-care with the feet and use of suitable shoes. Also, it was not possible to perform glycated hemoglobin for glycemic control of the study subjects, since this exam has to be requested by the doctor of the Basic Health Unit and made a schedule, which can take a few days. 


\title{
Conclusion
}

The results showed an association between low income, absence of family history of DM, and presence of callus in the feet with loss of coetaneous plantar sensitivity. These results point to the need for greater attention to the elderly with DM, especially those of low income, in regard to foot care and prevention of callus development, since loss of plantar skin sensibility is a risk factor for Development of diabetic foot. To that end, health professionals need to receive specific training that allows them to implement in their daily work, educational activities contextualized with the real health conditions of the elderly with Dm2.

\section{Acknowledgements}

We thank all study participants

\section{Funding}

No grants were received from funding agencies.

\section{Availability of Data and Materials}

Data supporting the findings is contained within the manuscript.

\section{Authors' Contributions}

FMNP and SSM contributed to the study design. FMNP was responsible for acquisition of the data and drafted the first manuscript with supervision of SSM. FMNP and EFT contributed to the analysis and interpretation of the data. All authors, revised the manuscript critically for important intellectual content. All authors read and approved the final manuscript.

\section{Ethics Approval and Consent to Participate}

Ethical approval was obtained from the Research and Ethical Committees(registration number: 353,067); Part of a randomized clinical trial registered with REBEC (RBR-8hfcz8). Written informed consent for participation in the study was obtained from the patients.

Consent for Publication

Informed consent for publication was obtained from the patients.

Competing Interests

The authors declare that they have no competing interests.

\author{
Abbreviations \\ DM: Diabetes Mellitus \\ DM2: Type 2 diabetes mellitus \\ IPAC: International Physical Activity Questionnaire \\ IQR: Interquartile range \\ Med: Median
}




\section{References}

1. Formosa C, Gatt A, Chockalingam N. Diabetic foot complications in Malta: Prevalence of risk factors. The Foot. 2012;22(4): 294-297.

2. Arredondo A, Reyes G. Health Disparities from Economic Burden of Diabetes in Middle-income Countries: Evidence from Mexico. Plos One. 2013;8(7): e68443.

3. Schmidt MI, Duncan BB, Mill JG. et al. Cohort Profile: Longitudinal Study of Adult Health (ELSA-Brasil). Int JEpidemiol. 2014;44(1):68-75.

4. Sartor CD, Watari R, Passaro AC, et al.Effects of a combined strengthening, stretching and functional training program versus usual-care on gait biomechanics and foot function for diabetic neuropathy: a randomized controlled trial. BMC Musculoskelet Disord. 2012;13: 36

5. Mazzini MCR, Blumer MG, Hoehne EL, et al. Diabetes mellitus risk screening of parents of private school students in the city of Jundiaí, São Paulo, Brazil. Rev Assoc Med Bras. 2013;59(2):136-142.

6. Smith AG, Singleton JR. Obesity and hyperlipidemia are risk factors for early diabetic neuropathy. $J$ Diabetes Complications. 2013;27(5):436-442.

7. Demakakos P, Hamer M, Stamatakis E, Steptoe A. Low-intensity physical activity is associated with reduced risk of incident type 2 diabetes in older adults: evidence from the English Longitudinal Study of Ageing. Diabetologia. 2010;53(9):1877-1885.

8. Brazil. Vigitel Brazil 2010: surveillance of risk and protective factors for chronic diseases through telephone survey. Secretariat of Health Surveillance, Secretariat of Strategic and Participative Management, Brasilia: Ministry of Health, 2011

9. Hurley L, Kelly L, Garrow AP, et al. A prospective study of risk factors for foot ulceration: The West of Ireland Diabetes Foot Study. Q J Med. 2013;106(12):1103-1110.

10. Bruun C, Siersma V, Guassora AD, Holstein P, Olivarius NF. Amputations and foot ulcers in patients newly diagnosed with Type 2 diabetes mellitus and observed for 19 years. The role of age, gender and co-morbidity. Diabet. Med. 2013;30(8): 964-972.

11. Lin SI, Chen YR, Chou CW. Association between sensoriomotor function and forward reach in patients with diabetes. Gait Posture. 2010;32(4): 581-585.

12. Guangren L, Chenglin S, Yanjun W, et al. A Clinical and neuropathological study of Chinese patients with diabetic peripheral neuropathy. Plos One. 2014;9(3): e91772.

13. Dyck PJ, Herrmann DN, Staff NP, Dyck PJB. Assessing Decreased Sensation and Increased Sensory Phenomena in Diabetic Polyneuropathies. Diabetes. 2013;62(11): 3677-3686.

14. Hohne A, Stark C, Bruggemann GP, Arampatzis A. Effects of reduced plantar cutaneous afferent feedback on locomotor adjustments in dynamics stability during perturbed walking. J Biomechanics. 2011;44(12): 2194-2200.

15. Caifa JS, Castro AA, Fidelis C, Santos VP, Silva ES. Integral attention to diabetic foot. $J$ Vasc Bras. 2011;10(4): 1-20.

16. Oliveira AF, De Marchi ACB, Leguisamo CP, Baldo GV, Wawginiak TA. Estimate of cost for diabetic foot treatment; how to prevent it and save funds. Ciên Saúde Colet. 2014;19(6).

17. Mendes TAB, Goldbaum M, Segri NJ, et al. Diabetes mellitus: factors associated with prevalence in the elderly, control measures and practices, and health services utilization in São Paulo, Brazil. Cad Saúde Pública. 2011;27(6):1233-1243.

18. Vieira-Santos ICR, Souza WV, Carvalho EF, et al. Prevalence of diabetic foot and associated factors in the family health units of the city of Recife, Pernambuco State, Brazil, in 2005. Cad. Saúde Pública. 2008;24(12): 2861-1270.

19. Stopa SR, Cesar CLG, Segri NJ, et al. Self-reported diabetes in older people: comparison of prevalences and control measures. Rev Saúde Pública. 2014;48(4): 554-562.

20. Brazil. Ministério da Saúde. Secretaria de atuação à saúde. Departamento de atenção básica. Manual do Pé Diabético: estratégias para o cuidado da pessoa com doença crônica. Brasília: Ministério da Saúde, 2016.

21. Benedetti TRB. Physical activity: A perspective of promoting health of the elderly in the city of Florianópolis. Doctoral thesis presented at the Health Sciences program. UDESC, 2004. 
22. Matsudo S, Araujo T, Matsudo V, et al. International Physical Activity Questionnaire IPAC: study validity and reproducibility in Brazil. Phys Activity Health. 2001;6(2):5-18.

23. WHO. World Health Organization Obesity.Preventing and managing the global epidemic: report of a WHO consultation. Geneva, World Health Organization. Technical report series, 1998; 894.

24. Simmons RW, Richardson C, Pozos R. Postural stability of diabetics patients with and without cutâneos sensory déficit in the foot. Diabetes Res Clin Pract. 1997;36:153-160.

25. Souza A, Nery CAS, Marciano LHSC, Garbino JA. Evaluation of peripheral neuropathy: correlation between skin sensitivity of the feet, clinical and electromyographic. Acta Fisiatr. 2005;12(3): 87-93.

26. Semmens J, Weinstein S, Ghent L, Teuber HL. Somatosensory changes after penetrating brain wounds in man. Cambridge, MA: Harvard University Press, 1960 apud Dellon AL. Evaluation of sensibility and re-education of sensation in the hand. Baltimore: Willians \& Wilkins, 2000; 99-175.

27. Tuttle LJ, Hastings MK, Mueller MJ. A moderate-intensity weight-bearing exercise program for a person with type 2 diabetes and peripheral neuropathy. Phys Ther. 2013;92(1):133-141.

28. Sims Jr DS, Cavanagh PR, Ulbrecht JS. Risk factors in the diabetic foot. Recognition and management. Phys Ther. 1988;68(12):1887-1902.

29. Trujilo A, Fleisher LK. Beyond Income, Access, and Knowledge: Factors Explaining the Education Gradient in Prevention Among Older Adults With Diabetes and Hypertension in Latin America. J Aging Health. 2013; 175(4): 315-324.

30. Aquino EML, Barreto SM, Bensenor IM, et al.Brazilian Longitudinal Study of Adult Health (ELSABrasil): Objectives and Design. Am JEpidemiol. 2012;175(4):315-324.

31. Cutler DM, Lleras-Muney A. Understanding differences in health behaviors by education. $J$ Health Economics. 2010;29(1): 1-28.

32. Tentolouris N, Voulgari C, Liatis S, et al. Moisture Status of the Skin of the Feet Assessed by the Visual Test Neuropad Correlates With Foot Ulceration in Diabetes. Diabetes care. 2010;33(5):1112-1114. 